\title{
Utilisation and Perception of Complementary and Alternative Therapies (CATs) among Obese and Overweight Individuals in a Malaysian Public University
}

\author{
Lua $\mathrm{PL}^{\mathrm{a}}$, Nurul Afiedia $\mathrm{R}^{1}$, Aryati $\mathrm{A}^{2}$, Mardiana $\mathrm{M}^{3}$, Myat $\mathrm{MTA}^{3}$, Farrahdilla $\mathrm{H}^{3}$ \\ ${ }^{a}$ Faculty of Pharmacy, Universiti Sultan Zainal Abidin (UniSZA), Kampus Besut, 22000 Besut, Terengganu, Malaysia. \\ ${ }^{\mathrm{b}}$ Faculty of Health Sciences, Universiti Sultan Zainal Abidin (UniSZA), Kampus Gong Badak, 21300 Kuala Nerus, Terengganu, Malaysia \\ ${ }^{c}$ Faculty of Medicine, Universiti Sultan Zainal Abidin (UniSZA), Kampus Perubatan, 20400 Kuala Terengganu, Malaysia
}

\section{ABSTRACT}

INTRODUCTION: Obesity and overweight are among the most serious public health issues that can threaten the well-being of individuals. Its increasing prevalence in Malaysia has inevitably caused many to additionally seek complementary and alternative therapies (CATs) to lose weight. This study intends to 1) assess the utilisation and perception toward CATs among obese and overweight participants and 2) assess applicability, practicality, reliability, and validity of the UPCATs-Malay. MATERIALS AND METHODS: It was conducted cross-sectionally on 30 students and staff. Responses were analysed using SPSS (v21). RESULTS: Among the participants (age = $26.17 \pm 8.23$ years; female $=66.7 \%$; students $=63.3 \%$ ), $40.0 \%$ were overweight and $60.0 \%$ were obese. Overall, $23.3 \%$ of the participants had previously used some types of CATs to lose weight, with herbal or dietary supplements $(20.0 \%)$ being the most common. Participants' attitudes towards CATs were mostly influenced by the internet (93.3\%). Most believed that CATs modalities were safe $(53.3 \%)$ and not a threat to public health $(70.0 \%)$. The majority of participants $(53.3 \%)$ were also considering joining any CATs-based weight management programmes. Additionally, the questionnaire was considered clear, comprehensive, and not difficult to complete ( $<5$ minutes). The overall reliability was 0.711 (domain range $=0.641-0.881$ ). The majority of individual items in UPCATs-Malay correlated better with their domains compared to other domains supporting validity. CONCLUSION: Overall, positive perceptions towards CATs were apparent and the questionnaire was reliable and valid. Further approaches should be taken especially on the identification of safe, viable CATs modalities and their role in weight management.

KEYWORDS: obesity, overweight, complementary and alternative therapies, weight loss

\section{INTRODUCTION}

According to the World Health Organization, obesity together with overweight problems are the second leading cause of preventable death worldwide in which the prevalence is rising significantly over the past two

Corresponding Author:

Prof. Dr. Lua Pei Lin

Faculty of Pharmacy,

Universiti Sultan Zainal Abidin (UniSZA),

Kampus Besut, 22000 Besut,

Terengganu, Malaysia,

Tel No: +609-6688520

Email : peilinlua@unisza.edu.my decades at $39 \%$ and $13 \%$, respectively. ${ }^{1}$ In Malaysia, the figures have similarly shown dramatic rises from $14 \%$ to $17 \%$ (obesity), and $20.7 \%$ to $30.0 \%$ (overweight). ${ }^{2}$ Currently, the treatments for excess weight include lifestyle modification such as diet, exercise, medications, and surgery. ${ }^{3}$ However, their compliances are generally poor and the obesity and overweight rates keep increasing globally. Further, almost $70 \%$ would regain their lost weight after the intervention, indicating that these strategies are sometimes ineffective for sustainable weight reduction. ${ }^{4}$ 
Nowadays, complementary and alternative therapies (CATs) are tremendously popular as an adjunct treatment for weight management as well as for improving health. CATs represents "a group of diverse medical and health care systems, practices, and products that are not presently considered to be part of conventional medicine such as biologically-based system, manipulative and body-based, mind-body therapies and traditional Asian medical systems".5-6

The global rapid increase in CATs uses for maintaining well-being ranges from $50 \%$ to $80 \%$ of the population. ${ }^{1,7}$ In Malaysia, CATs have long been practiced and it is estimated that about $18-37 \%$ individuals are using at least one form of CATs for various health problems, the most commonly-used being herbal-based products and dietary supplements. ${ }^{8-}$ 10 With an escalating rate of obesity and overweight, the demand for CATs is expected to keep soaring. A previous study among excess weight females in Jordan indicated that $40 \%$ of the participants used CATs for weight management. ${ }^{10}$ Similar studies have reported positive results but limited opinions exist regarding the utilisation of CATs for weight loss.

In Malaysia, such weight-focused studies are still scarce. Therefore, the current study was conducted to assess the utilisation and perception toward CATs and to evaluate the applicability, practicality, reliability, and validity of the Utilisation and Perception of CATsMalay questionnaire among obese and overweight individuals in a public university in Malaysia.

\section{MATERIALS AND METHODS}

\section{Setting and participants}

This was a cross-sectional study using convenience sampling in Universiti Sultan Zainal Abidin (UniSZA), Kuala Nerus, Malaysia. Participants had to be students and staff with body mass index (BMI) greater than $25 \mathrm{~kg} / \mathrm{m}^{2}$, between 18 to 60 years old, and understand the Malay language. The excluded participants were: (1) currently participating in other weight management programs; (2) having hearing problems; (3) suffering from chronic medical conditions; (4) pregnant or postmenopausal; (5) experiencing any psychotic symptoms. Thirty overweight or obese individuals according to a IMJM Volume 20 No.2, Apr 2021 general rule for the sampling of a pilot sample for the intervention study. ${ }^{11}$

\section{Ethical approval}

Ethical approval was obtained from the UniSZA Human Research Ethics Committee (UHREC) (ref: UniSZA/UHREC/2019/116).

\section{Instruments}

\section{Personal Information and Anthropometry Assessment}

A self-administered questionnaire was used to collect data on socio-demographic characteristics and anthropometric measurements (weight, height, BMI). Bodyweight was measured in light clothing and without shoes with Seca 813 weighing scale. Height was measured in an upright standing position with a portable stadiometer (Seca 213). BMI was calculated by dividing the measured body weight $(\mathrm{kg})$ by the squared measured height $\left(\mathrm{m}^{2}\right)$. The BMI classification as follows; (a) normal: $18.5-24.9 \mathrm{~kg} / \mathrm{m}^{2}$, (b) overweight: $25-29.9 \mathrm{~kg} / \mathrm{m}^{2}$, (c) obese type I: $30-34.9 \mathrm{~kg} / \mathrm{m}^{2}$, (d) obese type II: $35.0-39.9 \mathrm{~kg} / \mathrm{m}^{2}$, and (e) obese type III: $>40.0 \mathrm{~kg} / \mathrm{m}^{2}{ }^{12}$ All measurements were measured twice, and the average values were used in the analysis.

\section{Utilisation and Perception of Complementary and Alternative Therapies (UPCATs)- Malay}

This questionnaire was adapted from previous studies. ${ }^{13,14}$ The original questionnaire was translated from English into Malay by one independent translator. The translated versions had been compared, discussed, and modified before a preliminary Malay version of the UPCATs was agreed on. Later, backward translation of the preliminary Malay version into English was done by one independent, an expert translator. The English version was then compared with the original questionnaire for accuracy. Consequently, a provisional version of the UPCATs-Malay questionnaire was developed and ready for pilot testing.

The questionnaire was divided into four sections covering utilisation of CATs (25 items), source of information (11 items), and awareness and perceptions 
about CATs (10 items). The first and second parts of the questionnaire were evaluated by using multiple-choice questions. Participants' perceptions were assessed on a 5 -point Likert scale. Higher scores indicate a good perception of CATs.

\section{Applicability and Practicality Form}

This feedback form was adapted from a previous study in Malaysia. ${ }^{15}$ It consisted of five items that asked on the duration to complete the UPCATs questionnaire, clarity and understanding, comprehensiveness, and the spontaneous responses from participants. All items were open-ended questions except for Item 2 (4-point Likertscale) and item 4 (answered either 'yes' or 'no').

\section{Data Collection Procedures}

Upon agreeing to participate, participants were first asked to sign a written consent form before anthropometric measurements were taken. Participants later proceeded to complete demographic information and the UPCATs-Malay questionnaire. The duration spent answering the questionnaire was recorded using a stopwatch. The researchers remained with all participants during completing questionnaires to assist them with any difficult or unclear questions. Upon completion, the questionnaires were submitted to the researchers. A token of appreciation was distributed to the participants at the end of the study.

\section{Statistical analysis}

Statistical analysis was conducted using Statistical Package for Social Science (SPSS version 21.0). All descriptive analyses were presented as frequencies (n) and percentages $(\%)$. The internal consistency reliability was assessed via Cronbach's alpha (a) for overall and each domain of the UPCATs-Malay questionnaire. The a-value of 0.70 or greater indicates acceptable reliability. Spearman's rank correlation coefficient $\left(\underline{r}_{\mathrm{s}}\right)$ was used to determine the strength of the associations between an item and its domain or with other domains for validity purposes. The magnitude of $\underline{r}_{\mathrm{s}}>0.40$ between an item and its domain is considered as adequate evidence of convergent validity. ${ }^{22}$ Meanwhile, divergent validity was confirmed when an item weakly correlated with another domain than its domain $\left(r_{\mathrm{s}}<0.40\right) .{ }^{16}$

\section{RESULTS}

\section{Socio-demographic}

A total of thirty Malay Muslim students and staff participated in this study. The majority of the participants were females $(66.7 \%)$ and in the $18-28$ years age group $(70.0 \%)$. Besides, $70.0 \%$ of the participants were unmarried, had no income (56.7\%) and 63.3\% of them are students (18 undergraduates, one postgraduate). Most of them were obese (Class I: 36.7\%; Class II: 20.0\%; Class III: 3.3\%). The more comprehensive demographic data are presented in Table I.

Table I: Sociodemographic characteristics of participants $(n=30)$.

\begin{tabular}{|c|c|c|}
\hline Characteristics & $\begin{array}{l}\text { Frequency } \\
\text { (n) }\end{array}$ & $\begin{array}{l}\text { Percentages } \\
(\%)\end{array}$ \\
\hline \multicolumn{3}{|l|}{ Gender } \\
\hline Male & 10 & 33.3 \\
\hline Female & 20 & 66.7 \\
\hline \multicolumn{3}{|l|}{ Age (years) } \\
\hline $18-28$ & 21 & 70.0 \\
\hline $29-38$ & 6 & 20.0 \\
\hline $39-48$ & 2 & 6.7 \\
\hline $49-58$ & 1 & 3.3 \\
\hline \multicolumn{3}{|l|}{ Marital status } \\
\hline Single & 21 & 70.0 \\
\hline Married & 7 & 23.3 \\
\hline Divorced/Widowed & 2 & 6.7 \\
\hline \multicolumn{3}{|l|}{ Educational level } \\
\hline $\begin{array}{l}\text { Sijil Pelajaran Malaysia (SPM)/ } \\
\text { O-Level }\end{array}$ & 7 & 23.3 \\
\hline $\begin{array}{l}\text { STPM/Diploma/Asasi/ } \\
\text { Matrikulasi/Sijil/A-Level }\end{array}$ & 8 & 26.7 \\
\hline Degree & 14 & 46.7 \\
\hline $\begin{array}{l}\text { Master's degree/PhD } \\
\text { Occupation }\end{array}$ & 1 & 3.3 \\
\hline Staff & 11 & 36.7 \\
\hline Student & 19 & 63.3 \\
\hline \multicolumn{3}{|l|}{ Income } \\
\hline No income & 17 & 56.7 \\
\hline$\leq \mathrm{RM} 1,000 / \mathrm{USD} 230$ & 1 & 3.3 \\
\hline $\begin{array}{l}\text { RM 1,001 - RM 2,000/ USD } 230- \\
\text { USD } 460\end{array}$ & 4 & 13.3 \\
\hline $\begin{array}{l}\text { RM 2,001 - RM 3,000/ USD } \\
460.53 \text { - USD } 690\end{array}$ & 4 & 13.3 \\
\hline $\begin{array}{l}\text { RM 3,001 - RM 4,000/ USD } \\
690.68 \text { - USD } 920\end{array}$ & 2 & 6.7 \\
\hline$\geq$ RM 4,001/USD 920.83 & 2 & 6.7 \\
\hline \multicolumn{3}{|l|}{ BMI Status } \\
\hline Overweight (BMI: $18.5-24.9 \mathrm{~kg} / \mathrm{m}^{2}$ ) & 12 & 40.0 \\
\hline Obese type I (BMI: $25.0-29.9 \mathrm{~kg} / \mathrm{m}^{2}$ ) & 11 & 36.7 \\
\hline Obese type II (BMI: 30.0-34.9 kg/m²) & 6 & 20.0 \\
\hline Obese type III (BMI: > 40.0 kg/m²) & 1 & 3.3 \\
\hline
\end{tabular}


CATs Utilisation Patterns

Table II describes the habit of using CATs among the participants. Only $23.3 \%$ had the experience of using CATs with herbal or dietary supplements $(20.0 \%)$ were the most commonly utilised CATs, followed by manipulative and body-based therapies (3.3\%) and mind -body therapies $(3.3 \%)$. The majority had used CATs to prevent illness or for overall wellness $(16.7 \%)$ and as supplementary to conventional medication (16.7\%). Besides, 13.3\% utilised CATs either to treat a specific health condition or to reduce pain. Most participants were advised by their pharmacists $(10.0 \%)$, and family or friends $(10.0 \%)$ to try

Table II: CATs utilisation patterns among participants $(\mathrm{n}=30)$.

\begin{tabular}{|c|c|c|c|c|}
\hline \multirow[t]{2}{*}{ Items } & \multirow[t]{2}{*}{ Response } & \multicolumn{2}{|c|}{ Participants $(\mathbf{N}=30)$} & \multirow[t]{2}{*}{ n $(\%)$} \\
\hline & & $\begin{array}{l}\text { Students } \\
(n=19)\end{array}$ & Staff $(n=11)$ & \\
\hline \multirow[t]{2}{*}{ Usage of CATs } & Yes & 5 & 2 & $7(23.3)$ \\
\hline & No & 14 & 9 & $23(76.7)$ \\
\hline \multicolumn{5}{|l|}{ Type of CATs used: } \\
\hline \multirow[t]{2}{*}{ Herbal or dietary supplements } & Yes & 5 & 1 & $6(20.0)$ \\
\hline & No & 14 & 10 & $24(80.0)$ \\
\hline \multirow[t]{2}{*}{ Manipulative and body-based } & Yes & 0 & 1 & $1(3.3)$ \\
\hline & No & 19 & 10 & $29(96.7)$ \\
\hline \multirow[t]{2}{*}{ Mind-body } & Yes & 0 & 0 & 0 \\
\hline & No & 19 & 11 & $30(100.0)$ \\
\hline \multirow[t]{2}{*}{ Traditional alternative } & Yes & 1 & 0 & $1(3.3)$ \\
\hline & No & 18 & 11 & $29(96.7)$ \\
\hline \multirow[t]{2}{*}{ Others } & Yes & 0 & 0 & 0 \\
\hline & No & 19 & 11 & $30(100.0)$ \\
\hline \multicolumn{5}{|l|}{ Purpose of using CATs: } \\
\hline \multirow[t]{2}{*}{ To prevent illness/for overall wellness } & Yes & 3 & 2 & $5(16.7)$ \\
\hline & No & 16 & 9 & $25(83.3)$ \\
\hline \multirow[t]{2}{*}{ To treat a specific health condition } & Yes & 3 & 1 & $4(13.3)$ \\
\hline & No & 16 & 10 & $26(86.7)$ \\
\hline \multirow[t]{2}{*}{ To reduce pain } & Yes & 3 & 1 & $4(13.3)$ \\
\hline & No & 16 & 10 & $26(86.7)$ \\
\hline \multirow[t]{2}{*}{ As supplementary to conventional medicine } & Yes & 4 & 1 & $5(16.7)$ \\
\hline & No & 15 & 10 & $25(83.3)$ \\
\hline \multirow[t]{2}{*}{ Others } & Yes & 0 & 0 & 0 \\
\hline & No & 19 & 11 & $30(100.0)$ \\
\hline \multicolumn{5}{|l|}{ Used CATs on the advice of: } \\
\hline \multirow[t]{2}{*}{ Ownself } & Yes & 3 & 0 & $3(10.0)$ \\
\hline & No & 16 & 11 & $27(90.0)$ \\
\hline Doctor & Yes & 2 & 0 & $2(6.7)$ \\
\hline & No & 17 & 11 & $28(93.3)$ \\
\hline Pharmacist & Yes & 3 & 0 & $3(10.0)$ \\
\hline & No & 16 & 11 & $27(90.0)$ \\
\hline Family/friend & Yes & 3 & 0 & $3(10.0)$ \\
\hline & No & 16 & 11 & $27(90.0)$ \\
\hline Others & Yes & 1 & 0 & $1(3.3)$ \\
\hline & No & 18 & 10 & $29(96.7)$ \\
\hline Any discussion with health care provider (s) & Yes & 4 & 0 & $4(13.3)$ \\
\hline & No & 15 & 11 & $26(86.7)$ \\
\hline $\begin{array}{l}\text { Reasons not discussing with health care provid } \\
\text { (s): }\end{array}$ & & & & \\
\hline Don’t know should & Yes & 5 & 2 & $7(23.3)$ \\
\hline & No & 14 & 9 & $23(76.7)$ \\
\hline Not enough time during visits & Yes & 5 & 3 & $8(26.7)$ \\
\hline & No & 14 & 8 & $22(73.3)$ \\
\hline The health care provider didn't ask & Yes & 5 & 2 & $7(23.3)$ \\
\hline & No & 14 & 9 & $23(76.7)$ \\
\hline Don't know should discuss & Yes & 3 & 0 & $3(10.0)$ \\
\hline & No & 16 & 11 & $27(90.0)$ \\
\hline Not comfortable to discuss & Yes & 3 & 0 & $3(10.0)$ \\
\hline & No & 16 & 11 & $27(90.0)$ \\
\hline Health care provider have been dismissive & Yes & 0 & 1 & $1(3.3)$ \\
\hline & No & 19 & 10 & $29(96.7)$ \\
\hline Others & Yes & 0 & 0 & $0(0)$ \\
\hline & No & 19 & 11 & $30(100.0)$ \\
\hline Concomitant CATs usage with & Yes & 4 & 0 & $4(13.3)$ \\
\hline conventional medicines & No & 15 & 11 & $26(86.7)$ \\
\hline
\end{tabular}


alternative treatment modality and only $6.7 \%$ were recommended by doctors. In general, respondents had poor communication with their health care providers regarding CATs $(13.3 \%)$. The most common reasons for not discussing included not enough time during visits $(26.7 \%)$, not knowing they should discuss (23.3\%) and their health care provider did not ask about it (23.3\%). CAT was used concurrently with conventional medicine by $13.3 \%$ of participants.

\section{Sources of information about CATs}

Figure 1 describes the sources of information acquired by the participants. The majority of students $(60.0 \%)$ and staff $(33.3 \%)$ considered the internet as the primary source of information about CATs. Whereas the second source of information was from the pharmacists $(20.0 \%$ and $13.3 \%$, respectively), followed by family and friends (13.3\% and $10.0 \%$, respectively). The percentage total may exceed $100 \%$ as more than one source of information could be mentioned by the participants.

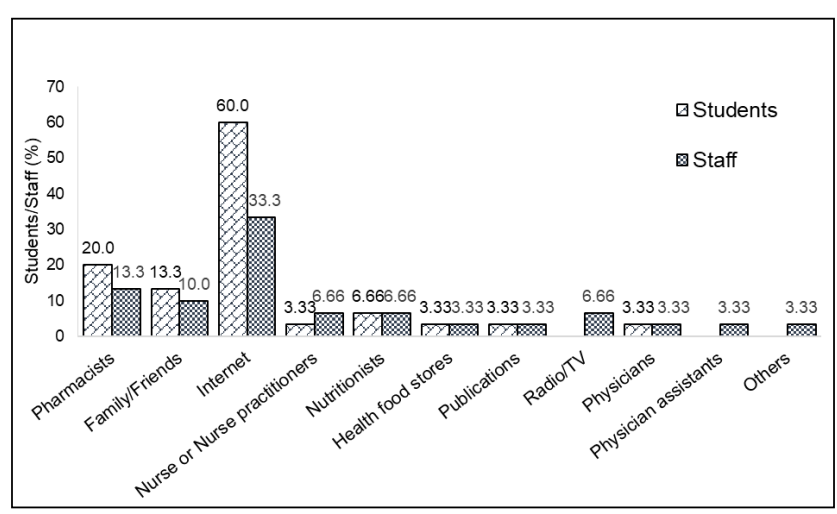

Figure 1. Sources of information about CATs.

\section{Perceptions towards CATS}

The majority of the participants were disagreed (53.3\%) or stayed neutral $(30.0 \%)$ about the notion that CATs' use is unsafe. Approximately $63.4 \%$ agreed that CATs beneficial for disease treatment and $56.7 \%$ agreed CATs use has fewer side effects than conventional medicine. The majority did not think that CATs is a threat to public health $(70.0 \%)$ and $63.3 \%$ strongly agreed that it was important to consult with healthcare professional before using CATs. About $60.0 \%$ were neutral with the statement on the benefits of CATs being related to their placebo effects. However, $60.0 \%$ of participants considered that the lack of scientific evidence is a barrier to CATs usage. A large proportion of the participants agreed $(53.3 \%)$ that clinical care should integrate the best of conventional therapies and CATs use while about 53.4\% were considering joining any weight management programme using CATs. The overall perceptions are presented in Table III.

Table III. Perceptions towards CATs $(n=30)$.

\begin{tabular}{|c|c|c|c|c|c|}
\hline \multirow{2}{*}{$\begin{array}{l}\text { Item (s) } \\
\text { (I believe } \\
\text { that...) }\end{array}$} & \multicolumn{5}{|c|}{ Frequency n (\%) } \\
\hline & $\begin{array}{l}\text { Strongly } \\
\text { agree }\end{array}$ & Agree & Neutral & Disagree & $\begin{array}{l}\text { Strongly } \\
\text { disagree }\end{array}$ \\
\hline $\begin{array}{l}\text { CAT use is } \\
\text { unsafe }\end{array}$ & 0 & $\begin{array}{c}1 \\
(3.3)\end{array}$ & $\begin{array}{c}9 \\
(30.0)\end{array}$ & $\begin{array}{c}16 \\
(53.3)\end{array}$ & $\begin{array}{c}4 \\
(13.3)\end{array}$ \\
\hline $\begin{array}{l}\text { CAT use is not } \\
\text { an appropriate } \\
\text { treatment in } \\
\text { any disease }\end{array}$ & 0 & $\begin{array}{c}1 \\
(3.3)\end{array}$ & $\begin{array}{c}10 \\
(33.3)\end{array}$ & $\begin{array}{c}17 \\
(56.7)\end{array}$ & $\begin{array}{c}2 \\
(6.7)\end{array}$ \\
\hline $\begin{array}{l}\text { CAT use has } \\
\text { fewer side } \\
\text { effects } \\
\text { compared to } \\
\text { conventional } \\
\text { medicine }\end{array}$ & 0 & $\begin{array}{c}17 \\
(56.7)\end{array}$ & $\begin{array}{c}6 \\
(20.0)\end{array}$ & $\begin{array}{c}6 \\
(20.0)\end{array}$ & $\begin{array}{c}1 \\
(3.3)\end{array}$ \\
\hline $\begin{array}{l}\text { CAT is a threat } \\
\text { to public health }\end{array}$ & 0 & $\begin{array}{c}2 \\
(6.7)\end{array}$ & $\begin{array}{c}7 \\
(23.3)\end{array}$ & $\begin{array}{c}20 \\
(66.7)\end{array}$ & $\begin{array}{c}1 \\
(3.3)\end{array}$ \\
\hline $\begin{array}{l}\text { It is important } \\
\text { to consult any } \\
\text { healthcare } \\
\text { professional } \\
\text { before CAT } \\
\text { use }\end{array}$ & $\begin{array}{c}10 \\
(33.3)\end{array}$ & $\begin{array}{c}9 \\
(30.0)\end{array}$ & $\begin{array}{c}6 \\
(20.0)\end{array}$ & $\begin{array}{c}2 \\
(6.7)\end{array}$ & $\begin{array}{c}3 \\
(10.0)\end{array}$ \\
\hline $\begin{array}{l}\text { CAT benefits } \\
\text { are related to } \\
\text { their placebo } \\
\text { effects }\end{array}$ & 0 & $\begin{array}{c}8 \\
(26.7)\end{array}$ & $\begin{array}{c}18 \\
(60.0)\end{array}$ & $\begin{array}{c}3 \\
(10.0)\end{array}$ & $\begin{array}{c}1 \\
(3.3)\end{array}$ \\
\hline $\begin{array}{l}\text { Lack of } \\
\text { scientific } \\
\text { evidence is a } \\
\text { barrier toward } \\
\text { CAT use }\end{array}$ & 0 & $\begin{array}{c}18 \\
(60.0)\end{array}$ & $\begin{array}{c}9 \\
(30.0)\end{array}$ & $\begin{array}{c}3 \\
(10.0)\end{array}$ & 0 \\
\hline $\begin{array}{l}\text { The concern of } \\
\text { legal issues is a } \\
\text { barrier toward } \\
\text { CAT use }\end{array}$ & $\begin{array}{c}3 \\
(10.0)\end{array}$ & $\begin{array}{c}12 \\
(40.0)\end{array}$ & $\begin{array}{c}9 \\
(30.0)\end{array}$ & $\begin{array}{c}4 \\
(13.3)\end{array}$ & $\begin{array}{c}2 \\
(6.7)\end{array}$ \\
\hline $\begin{array}{l}\text { Clinical care } \\
\text { should } \\
\text { integrate the } \\
\text { best of } \\
\text { conventional } \\
\text { and CAT use }\end{array}$ & $\begin{array}{c}6 \\
(20.0)\end{array}$ & $\begin{array}{c}10 \\
(33.3)\end{array}$ & $\begin{array}{c}11 \\
(36.7)\end{array}$ & $\begin{array}{c}2 \\
(6.7)\end{array}$ & $\begin{array}{c}1 \\
(3.3)\end{array}$ \\
\hline $\begin{array}{l}\text { I will consider } \\
\text { joining any } \\
\text { programme } \\
\text { using CAT to } \\
\text { lose weight }\end{array}$ & $\begin{array}{c}2 \\
(6.7)\end{array}$ & $\begin{array}{c}14 \\
(46.7)\end{array}$ & $\begin{array}{c}10 \\
(33.3)\end{array}$ & $\begin{array}{c}2 \\
(6.7)\end{array}$ & $\begin{array}{c}2 \\
(6.7)\end{array}$ \\
\hline
\end{tabular}

\section{Applicability, Practicality, Reliability, and Validity of UPCATs-Malay}

The majority of participants took an average of 3.18 minutes $(\mathrm{SD}= \pm 0.837$, range $=2-5$ minutes $)$ to complete 
the questionnaire. Most of them considered the questions and instructions to be "clear" ( $n=15,50 \%)$ and "very clear" ( $n=12,40 \%)$ respectively. Only three participants stated that some of the items (items number 6 and 9 in domain Perceptions towards CATs) were "not clear" as they did not understand the term 'placebo' and 'integration'. All participants $(100 \%)$ thought UPCATsMalay was comprehensive and had no difficulties completing the questionnaire.

The overall Cronbach alpha (a) was 0.711. This internal consistency reliability gauge for all domains exceeded 0.70 except for the domain on perception towards CATs which was considered moderately acceptable $(a=0.641) \quad$ (Table IV). Within UPCATs itself, all individual items produced moderate correlations (corrected for overlap) with their respective domains than with other domains $\left(r_{s} \geq 0.30\right)$ except for the nine items in the Usage of CATs, Sources of information, and Perceptions towards CATs (items number 2, 14, 17, 18, 19, 23, 35, 36 and 38). These findings demonstrated overall convergent validity. Subsequently, most items in dissimilar domains illustrated divergent validity as they showed weak correlations $\left(\underline{r}_{s}=0.00-0.29\right)$ or moderate associations $\left(r_{s}=0.30-0.38\right)$ with each other.

Table IV: Internal consistency measured by Cronbach's alpha of UPCATs-Malay domains.

\begin{tabular}{ll}
\hline Variable & Cronbach's alpha (a) \\
\hline Usage of CATs & 0.707 \\
Sources of information & 0.881 \\
Perceptions towards CATs & 0.641 \\
Overall & 0.711 \\
\hline
\end{tabular}

\section{DISCUSSION}

Although the use of CATs is increasing, there are very few published studies documenting the extent of use and perceptions towards CATs for weight management. ${ }^{10}$ The current study showed that the utilisation of CATs among this population was slightly more than the general prevalence of CATs used in Malaysia, based on a survey in 2015 which was nearly $30 \%$. However, the respondents in NHMS (2015) involved the general population whereas, in our study, data were collected from obese and overweight individuals. There was also a study done in Jordan which indicated approximately twice higher CATs use among excess weight females $(40.0 \%)$ than that found in our study. ${ }^{10}$ This difference seen was probably because all the other studies were conducted in various community settings while this study was only restricted to a public university. Additionally, the accessibility and availability of CATs modalities may have influenced an individual's usage. ${ }^{17}$

Herbal or dietary supplements were the most preferred CATs in this study $(20.0 \%)$, probably due to them being readily available over the counter (may purchase from supermarkets, health food stores, online) and affordable cost in comparison to conventional medicine. This finding is comparable to an earlier general survey in Malaysia where herbal-based products were the most commonly used CATs among the population. ${ }^{9}$ This is similar to a study in the UK, where easier to access and less expensive CATs products were found to be the major reasons for their use. ${ }^{18}$ Majority of the participants used CATs to prevent illness (16.7\%) and as additional food supplements (16.7\%) - a phenomenon which may be due to the common belief that natural food is safe and possess fewer adverse effects. The literature has previously reported that participants' choice of using CATs was not only due to the availability of natural foods, but also because it was considered healthier and did not have the adverse effects as conventional medicines. ${ }^{25,26}$ Preventing complications from conventional medicine had also been cited as a reason for its common practice. ${ }^{19-20}$

On a separate issue, the majority of the respondents have not discussed their CATs usage with their health care providers. This illustrates a rather poor communication between the participants and their health care providers, which could be due to the participants' assumption that it was not a necessary thing to do. It could also result from being fearful of the health care providers' reactions. This finding was comparable to other studies which revealed that most participants thought discussing CATs with physicians was not important due to reasons such as lack of knowledge and awareness. ${ }^{17,21}$ Nonetheless, most subjects used CATs as advised by the pharmacists, family, and friends suggesting the existence of their confidence in the pharmacists as well as their strong ties and trust towards family members in Malaysia. It was 
demonstrated from an earlier report that $31.3 \%$ of the participants started to utilise CATs on the advice of family and friends to help individuals achieve their goal and improving motivation. ${ }^{22}$

In this study, the internet, pharmacists, family, and friends were the main sources of information when it came to matters regarding CATs. This trend of information-seeking is already a common practice in many countries such as the obese and overweight in Jordan who turned to the internet, family, and friends as their main resources. ${ }^{10}$ The fact that the internet is a popular and notable information source undoubtedly hinges on its ease of accessibility (most people own smartphones or laptops/iPads/tablets), availability (very wide coverage nowadays in many countries), and affordability (free WiFi services in common public places). However, the internet and social media can sometimes be unreliable due to a lack of properly-cited scientific evidence and thus, appropriate reports on evidence-based CATs are constantly in need.

Interestingly, this research also discovered that majority of the subjects showed positive perceptions towards CATs. This is consistent with another study that also claimed a similar finding. ${ }^{10}$ Most female participants (who constituted more than $50 \%$ of the respondents) agreed that CATs were safe and not a threat to public health. This could be due to the reason those female participants are more interested in using CATs for weight management compared to males. According to Alwhaibi et al.,23 females were likely to be more responsive and have a greater desire in seeking CATs benefits to improve their health and well-being. Furthermore, women are more concerned about their appearance and drive for smaller body image because of the influence from social media (Facebook, Instagram, etc,) which features slim appearance as perfect and more acceptable in society. ${ }^{24}$

In contrast, lack of scientific evidence on the effectiveness was the major barrier of CAT use. There is a need for evidence-based CATs information to be spread by CATs professionals and other healthcare providers as suggested before. ${ }^{25}$ Based on the results, it was observed that legal concern may be one of the reasons that influenced individual's preferences towards CATs. Kwon et al. ${ }^{26}$ also reported that CATs regulation was important to ensure the safety and standardisation of CATs practices. Accordingly, the Malaysian government has gazetted the Traditional and Complementary Medicine Act 2013(4) which is in line with the WHO strategy to regulate the CATs practitioners and practices. This attempt includes standardisation and accreditation of education and training of recognised practices, the establishment of CATs units in selected government hospitals, promotion of safe use of CATs, and increasing the number of research and development. ${ }^{9}$ Besides, participants were uncertain about the benefits of CATs which could be related to their placebo effects. This might be due to the lack of knowledge and exposure to CATs. This is well supported by literature that reported the positive perceptions of CATs following the introduction of CATs courses into the present curriculum. ${ }^{27,28}$ At the same time, developing CATs education programs could help improve an individual's knowledge related to CATs and protect them from unexpected adverse effects of CATs.

From the perspectives of the respondents, the UPCATs -Malay was generally acceptable -they found it to be practical as it needed minimal time to complete. The majority of them stated that the questionnaire is clear, comprehensive, and possessing a suitable basic construct, indicates acceptability and applicability of the questionnaire. The findings of the reliability tests surpassed the Cronbach's alpha coefficient threshold of 0.70.29 However, domain Perceptions towards CATs were moderate and likely due to a low number of questions and poorly interrelated between items. A moderate correlation was also demonstrated between their domain compared to other domains, exhibit convergent validity. These findings have been confirmed by previous studies from the literature. ${ }^{14,30}$

Anyhow, some limitations of this study need mentioning. Among others, the small number of participants which was coincidentally all Malay Muslims, could not permit a more thorough generalisation. Since the method was based on convenience sampling, the overall outcomes may not represent the actual results from the larger segments of obese or overweight individuals in the country. Nevertheless, the strength of this study is that it has explored a public health issue that is of pertinent interest to healthcare researchers in 
Malaysia and worldwide. The findings are still worthy of some contribution to public health education and CATs literature, and it may become the basis to fully utilise CATs' potential in combating weight problems in near future.

\section{CONCLUSION}

The present study demonstrated that only one-fifth of the respondents had ever used CATs for weight management within the last twelve months, in which the most common types were herbal and dietary supplements. The main sources of information were the internet, followed by the pharmacists, family, and friends. Despite that, positive perceptions towards CATs were found, with more than half believing that CATs were safe and not a threat to public health. Additionally, the questionnaire was also considered clear, comprehensive, and reliable for this current population.

\section{Conflicts of interest}

None declared.

\section{ACKNOWLEDGEMENTS}

We gratefully acknowledged all the participants who had been involved. This study was supported by a research grant from Universiti Sultan Zainal Abidin - UNISZA Mentor-Mentee Research Grant R0046-R001. This paper also was dedicated to our team member, the late Madam Haszalina Hassan who had passed away on 15th March 2020.

\section{REFERENCES}

1. World Health Organization (WHO). Obesity and Overweight Fact Sheet. Geneva:WHO, 2019.

2. Institute for Public Health. National Health and Morbidity Survey 2015 (NHMS 2015). Vol. II: Non-Communicable Diseases, Risk Factors \& Other Health Problems. Kuala Lumpur: Ministry of Health Malaysia; 2015.

3. Kim SY, Shin SI, Park YJ. Effect of acupuncture and intervention types on weight los: a systematic review and meta-analysis. Obes Rev 2018; 19:11.

4. Marti T, Foth D, Weidlinger S, Stute V, Stute P.
Lastiing effect of nutritional and exercise intervention on body weight: A comprehensive literature review. Public Health Nutr 2019; 2:3.

5. National Centre for Complementary and Integrative Health Medicine (NCCIH). Complementary, alternative, or integrative health: what's in a name? Maryland: USA, 2018.

6. Nuffer M. Integrative health and medicine: Dietary supplements and modalities for the treatment of obesity. In: Nutrition in the Prevention and Treatment of Abdominal Obesity (second edition). United States: Academic Press, 2019: 393-408.

7. Kristoffersen AE, Stub T, Musial F, et al. Prevalence and reasons for intentional use of complementary and alternative medicine as an adjunct to future visits to a medical doctor for chronic disease. BMC Complement Altern Med 2018; 18: 109.

8. Noraidatulakma A, Boekhtiar B, Afza EAP,met al. Utilization of complementary medicine in multiethnic population: The Malaysian cohort study. J Evid Bsed Integr Med 2018; 23.

9. Institute for Public Health (IPH). National Health and Morbidity Survey 2015 (NHMS 2015). Vol. IV: Traditional \& Complementary Medicine; 2015.

10. Halib H, Hamdan NA, Hussin N, Shafie N. The association between the use of complementary and alternative medicine (CAM) with healthrelated quality of life and anthropometric indices among university's staff. Malaysian J Public Health Med. 2017; 2: 74-81.

11. Shehadeh MB, Suaifan GAR, Abu-Odeh AM, Darwish RM. Complementary and alternative medicine use among females in Jordan; a ommunity-based survey. East Mediterr Health J. 2019; 25.

12. Sorzano COS, Tabas-Madrid D, Nunez F, Fernandez-Criado C, Naranjo A. Sample size for pilot studies and precision driven experiments. Lab Anim-UK 2018; 20 March.

13. World Health Organisation (WHO). Physical status: the use and interpretation of anthropometry: report of a world health organization (WHO) expert committee. Geneva: Switzerland, 1998.

14. Jamshed SQ, Khan MU, Ahmad A, Elkami RM. Knowledge, perceptions and attitudes toward 
complementary and alternative medicines among pharmacy students of a Malaysian Public University. J Pharm Bioall Sci 2016; 8:34-38.

15. The national Center for Complementary and Alternative Medicine (NCCAM). What people aged 50 and older discuss with their health care providers. AARP and National Center for Complementary and Alternative Medicine Survey Report. Washington: DC. 2013.

16. Lua PL, Wong SY. The reliability of the Malay versions of hospital anxiety depression scale (HADS) and McGill Quality of life questionnaire (MQOL) among a group of patients with cancer in Malaysia. Malaysian Journal of Psychiatry [serial online] 2012; 21:25-37.

17. Boateng GO, Neilands TB, Frongillo EA, MelgarQuinonez HR, Young SL. Best practices for developing and validating scales for health, social and behavioral researh:a primer. Public Health Front 2018; 6:149.

18. Kew Y, Chia YL, Lai SM, et al. Traditional and complementary medicine (TCM) among study population with cardiovascular risk: use and substitution for conventional medicine in Pahang, Malaysia. Med J Malaysia 2015; 70:86-93.

19. Zahn R, Perry N, Perry E, Mukaetova-Ladinska EB. Use of herbal medicines: pilot survey of UK users' views. Complement Ther Med 2019; 44:83-90.

20. Bahall M. Use of complementary and alternative medicine by patients with end-stage renal disease on haemodialysis in Trinidad: a descriptive study. BMC Complement Altern Med 2017; 17:250.

21. Ramdzan SN, Pinnock H, Liew SM et al. Perceptions of complementary/alternative medicine use and influence on evidence-based asthma medicine adherence in Malaysia children. NPJ Prim Care Respir Med 2019; 29:5.

22. Roy V, Gupta M, Ghosh RK. Perception, attitude and usage of complementary and alternative medicine among doctors and patients in a tertiary care hospital in India. Indian J Pharmacol 2015; 47:137-142.

23. Latte-Naor S, Sidlow R, Sun L, i QS, Mao JJ. Influence of family on expected benefits of complementary and alternative medicine (CAM) in cancer patients. Support Care Cancer 2018; 26:20632069.

24. Alwhaibi M, Alruthia Y, Meraya AM. Gender differences in the prevalence of complementary and alternative medicine utilization among adults with arthritis in the United States. Evid Based Complement Alternat Med 2019. Article ID 8739170.

25. Fardouly J, Vartanian LR. Social media and body image concerns: current research and future directions. Curr Opin Psychol 2016; 9:1-5.

26. Lua PL. The role of complementary indigenous Malay therapies: persepectives from palliative care patients. J Complement Integr Med. 2011; 8.

27. Veziari Y, Leach MJ, Kumar S. Barriers to the conduct and application of research in complementary and alternative medicine: a systematic review. BMC Complement Altern Med 2017; 17:166.

28. Kwon JH, Lee SC, Lee MA, et al. Behaviors and attitudes toward the use of complementary and alternative medicine among Korean cancer patients. Cancer Res Treat 2019; 51:851-880.

29. Ashraf M, Saeed H, Saleem Z, Rathore HA, Rasool F, Tahir E. et al. A cross-sectional assessment of knowledge, attitudes and self-perceived effectiveness of complementary medicine among pharmacy and non-pharmacy students. BMC Complement Altern Med 2019; 19:95.

30. Xie H, Sang T, Li W, et al. A survey on perceptions of complementary and alternative medicine among undergraduates in China. Evid Based Complement Altern Med 2020. Article ID:9091051

31. Taber KS. The use of Cronbach's alpha when developing and reporting research instruments in science education. Res Science Educ 2018; 48:12731296.

32. Barnes PM, Bloom B, Nahin R. Complementary and Alternative Medicine Use Among Adults and Children. CDC National Health Statistics Reports \#12. United States, 2008. 